\title{
A Survey on Application of Maturity Models for Smart Grid: Review of the State-of-the-Art
}

\author{
Mathias Uslar \\ OFFIS \\ Institut for Information Technology \\ 26121 Oldenburg, Germany \\ mathias.uslar@offis.de
}

\author{
Julia Masurkewitz \\ OFFIS \\ Institut for Information Technology \\ 26121 Oldenburg, Germany \\ julia.masurkewitz@offis.de
}

\begin{abstract}
More and more different organizations are necessarily being involved in realizing the Smart Grid, but each of them has to fulfill a different role concerning the overall transition. Stakeholders from the transmission and from the distribution layer must be considered. Deriving from this, a large variety of topics and viewpoints are involved. The future Smart Grid architecture will thus be highly dynamic and complex. Guidance for the enterprises, regarding comparability and measurability of different activities and showing optimization potential for the Smart Grid, is urgently needed. A promising approach is to combine the approved method of the Smart Grid Architecture Model (SGAM) Use Case modeling method and a maturity model developed thereupon. A benefit for the development of the sustainable energy system of the future is, that the assessment of Smart Grid technology, concerning their interoperability and interaction, helps creating a common and organization crosscutting understanding. This paper gives an overall overview about maturity models and their benefits. Additionally, a classification scheme for maturity models is outlined in a first draft. This classification scheme should guide the selection of characteristics for developing a new maturity model.
\end{abstract}

\section{Keywords - Maturity Model, SGAM, SG IMM, SGMM}

\section{INTRODUCTION}

At the moment, the whole energy industry is in a phase of fundamental change. The regulatory guideline to the nuclear power phase-out in favor of the integration of renewable energy and of the reduction of the greenhouse gas emission puts high requirements on the energy industry. These objectives make the integration of renewable energy a central cornerstone for which crucial measure must be realized in the upcoming years. Regarding the political decisions for a more sustainable development of the energy system, one of the upcoming challenges is to design and define all necessary processes, regulations, technical solutions and additional tools to realize this fundamental change of the energy sector. But the essential challenge for the transformation of the existing energy system to the energy system of the future is still the integration of renewable energy producers into the system. Thus, all kinds of different research along the whole supply chain in this field is done.

Current research and application fields contain load and generation management, system stability, system reliability and

This research has been supported by the BMWi and BMBF, under "Zukunftsfähige Stromnetze" project Green Access (grant no: 03ET7534A) Any opinions, findings and conclusions or recommendations expressed in this material are those of the authors and do not necessarily reflect those of the BMWi or BMBF. efficiency. All solution ideas and developed concepts have in common, that the information and communication technologies have a key function. Taking together these attempts, the design and an implementation blueprint of the Smart Grid is developed. The Smart Grid consists of a huge variety of technologies and consecutively developed services. An increasing challenge for the distribution system operators is to assess the Smart Grid technologies concerning implementation, interoperability, efficiency, cost-benefit, etc. Specialized maturity models and qualitative evaluations can provide a thorough analysis of the Smart Grid and help the distribution system operators in their decision-making processes for developing a sustainable energy supply.

The challenge is that more and more different organizations are necessarily being involved in realizing the Smart Grid, but each of them has to fulfill a different role concerning the overall vision. Stakeholders from the transmission and from the distribution layer must be considered. Deriving from this, a large variety of topics and viewpoints (like electrotechnical and ICT) are involved. Aspects like different data models, interfaces and functionalities must be considered originating from the diverse requirements of the stakeholders. The future Smart Grid architecture will thus be highly dynamic and complex. Guidance for the enterprises, regarding comparability and measurability of different activities and showing optimization potential for the Smart Grid, is urgently needed. For both, documenting the progress and the communication with internal and external partner's maturity models can support the activities of the organization.

A promising approach is to combine the approved method of the Smart Grid Architecture Model (SGAM) Use Case modeling method and a maturity model developed thereupon. Reasons for exploring this fusion are that the SGAM modeling process is, firstly, already standardized in form of IEC / PAS 62559. Secondly, it is yet accepted by enterprises and by (their) research facilities. Thirdly, the SGAM is a method of presentation and communication cross-cutting a company's hierarchical levels from management to engineering. Especially this potential is worth being used in a maturity model. Additionally, the attempts of integrating security aspects into the SGAM also represent a further incentive to combine it with a maturity model [1], [2]. 
This paper aims at focusing on a more peripheral but still necessary aspect of the development of a more sustainable energy system. To explain this it is worthwhile to remember a core aspect of sustainable development, meaning a development which meets the necessities of the current societies without endangering the needs and the foundation of future generations [3]. The present political energy 'projects' definitely meet this description. Overall, the transformation of the energy system is not straightforward. Regarding the possible ICT solutions, which support and add additional benefits to societal projects, a huge variety of possible solutions have to be considered. A Smart Grid Maturity Model which focuses on the development process of Smart Grid with a broad perspective helps as an additional tool in two different ways. Firstly of all it outlines concepts for the organization of how to deploy Smart Grid and can help to reduce double investments or conventional grid expansion. Secondly, it helps organizations to proof and reproof their Smart Grid development concepts in order to follow the best paths for development. Therefore this paper is structured as follows: Section two gives an overall overview about maturity models and their benefits. Section three introduces general maturity models. Section five focuses on domain-specific maturity models for the Smart Grid and cybersecurity. Section four and six summarize the afore-mentioned sections. In part seven, a first classification scheme for maturity models is presented. This classification scheme should guide the selection of characteristics for developing a new maturity model. And finally, in part eight an outlook about possible progression of existing models towards an European model with the focus of the distribution layers is given. Furthermore, in the conclusion of the paper a glimpse of the possibility to merge a Smart Grid maturity model and SGAM is presented.

\section{MATURITY MODELS AND THEIR BENEFITS}

In the following first subsection the general conception of maturity models will be outlined. The second subsection introduces the benefits of applying maturity models from an organizational perspective.

\section{A. Maturity Models}

Maturity models are already a widespread instrument for the assessment of processes (see PEMM), of software development (see CMMI), business skills (see OPM3 [4]), cybersecurity (see ES-C2M2), and many more relevant issues. Overall, a total of more than 100 maturity models [5] and more than 1000 academic papers can be found which analyze, refine or develop maturity models [6]. Despite the diversity of maturity models in terms of their objectives, between most of them a lot of similarities can be found, which exceeds the mere benefits of maturity models in general. In short, maturity models are step-based models for specific objects, which are decomposed into further units in the concrete analyses [7]. Most of the maturity models measure or evaluate each unit separately. The maturity level provides information about the current state of development of the observed object. Thus, maturity models serve as evaluation models, but can additionally function as explanatory and optimizing models [8].
Maturity models can be basically distinguished into two different types of models. The difference can be based on their focus. On the one hand, there are models that relate to enterprise cross-cutting issues such as processes or business skills [9]. The analyzed objects of this kind of models can be found in all companies and branches, and thus these models can be applied to all of them. On the other hand, there are models which have been developed to evaluate specific issues such as the Smart Grid or interoperability in Smart Grid. Therefore, these models have relevance merely for a few enterprises and mostly for one domain only.

\section{B. Benefits of Maturity Models}

In general, the benefits of maturity models are that they allow establishing comparable assessments. Another advantage of them is that they inform the enterprise about the current state of development concerning a specific issue. Based on these analytical results, optimization requirements can be deduced. The levels of detail for these requirements vary in the different kinds of models.

A uniform documentation is compiled during the evaluation process. This documentation can be used for internal communication and coordination on the one hand, and for the communication with external parties on the other. The results of the maturity evaluation are particularly and often used in benchmarking processes.

Another advantage of maturity models originates when they are being compared to individual process improvement initiatives. The main benefit lies there in the determination of single maturity levels that can be performed and should be performed as a regular process. The changes (positive and negative ones) and the overall developments of the company can be consistently recognized by deploying the same procedure. This helps to form long-term targeted positioning of organizations and fosters transparent and comparable information.

Depending on the concrete model, maturity models can also support the identification of weak points or gaps, the introduction of new processes, and the quality control by introducing them. One of the central elements of maturity models, which as well explain the popularity of these models, is the inclusion of experience or best practice procedures of other companies into the concept of the model. This gives each company the advantage to benefit from the experience of others by using a single model. However, the greatest benefit is still the identification of existing potentials and how these can be used in the future.

A general criticism of maturity models concerns the assumption that all enterprises will have one and the same progress. On this point flexibility is given in most models only to a limited degree. Other criticisms focus on the oversimplified reality or their lack of empirical foundation [10].

For developing a new Smart Grid specific model with a special focus on the distribution layer, several questions need to be answered and lots of preparatory work must be done. The main question is why a new model is necessary. But this question can only be sufficiently answered after investigating 
existing models. In section six this question will be picked up again. To prepare the development of a maturity model the method should be explained. Performing this task seems problematic, because there are shortcomings in the theory of developing maturity models [9].

One design method is presented by de Bruin [11] or Becker et al. [12]. Pöppelbuß and Röglinger are trying to define distinct design principles for maturity models, which include e.g. differentiation from related maturity models, purpose of use, available levels of granularity of maturation, improvement measures, documentation, etc. [10].

Another option consists of adopting existing models to new demands. The following proceeding will be conducted in reference to Rohjans and Uslar [13]. An appropriate maturity model must be selected, which functions as the origination basis. Therefore, a comparison of existing models and an understanding of suitable selection criteria are necessary. The criteria should be in accordance with the goals and the field of application of the new maturity model. Hence, the domain under consideration needs to be analyzed in depth in order to identify characteristics that demand for differences in the assessment of their maturity [13]. Here, concrete requirements and focus areas for the model should be defined.

\section{GENERAL MATURITY MODELS}

As already mentioned in the section above, a basic differentiation is assumed for maturity models. Following these, this section introduces some general maturity models and the fifth section some domain-specific maturity models. The concentration will lie on the energy domain, i.e. the Smart Grid. The following models have been chosen for different reasons: The CMMI is one of the widespread and universal models, consisting of one general framework and three variants for specific applications. This overall structure makes it especially interesting. In comparison to the other models, PEMM and BPMM are less known. PEMM is chosen, because it was developed by a consultancy and not by a consortium or research institutes. The reason for choosing SPICE is, that it is an ISO / IEC standard. EDEN has been chosen for two reasons. Firstly, it is a relatively detailed model for business process management, and secondly it is developed in Germany; so European specifics should be considered. BPMM represents a model focusing on business processes, but its origin and strong relation to CMMI make it worth considering. Choosing EDEN and BPMM, which are similar regarding their focus and their relation to CMMI, is based on the interest in their different forms of realization. Of course another selection of maturity models is possible, like taking into account more maturity models with different focuses or to concentrate on domainspecific maturity models, because the aim is to develop a domain-specific one. During the actual comparison, more models will be considered, but for a first review the above mentioned are sufficient.

\section{A. Capability Maturity Model Integration (CMMI)}

A widespread maturity model is the Capability Maturity Model Integration (CMMI) developed by the Software Engineering Institute (SEI) in Pittsburgh. The focus of this maturity model is to evaluate companies concerning their software development. CMMI basically serves the analysis and optimization of processes within an organization. The model exists in three discernible variants:

First, there is the CMMI for Development (CMMI-DEV). It concentrates on processes for the development of products and services. This encompasses sectors such as project management, process management, system development and hard- and software development as well as further processes concerning development [14]. Secondly, there is the CMMI for Services which includes the activities needed for establishing, delivering and managing services, i.e. work management, process management, service establishment, service delivery and support [15]. Thirdly, there is the CMMI for Acquisation (CMMI-ACQ) which is focused on the acquisition of necessary capabilities [16].

However, all three variants of CMMI are built upon a common CMMI framework, which provides the basic elements that are complemented by the variants to suit the respective needs. In general, CMMI and its variants are composed of best practice suggestions which are meant to refine and optimize the specific focus areas of the discernible variants.

Every CMMI encompasses various process areas ${ }^{1}$, for instance risk management and organizational process performance. These process areas include different components of CMMI, generic goals and generic practices. The interrelation of the single components is described in the following diagram (see Fig. 1):

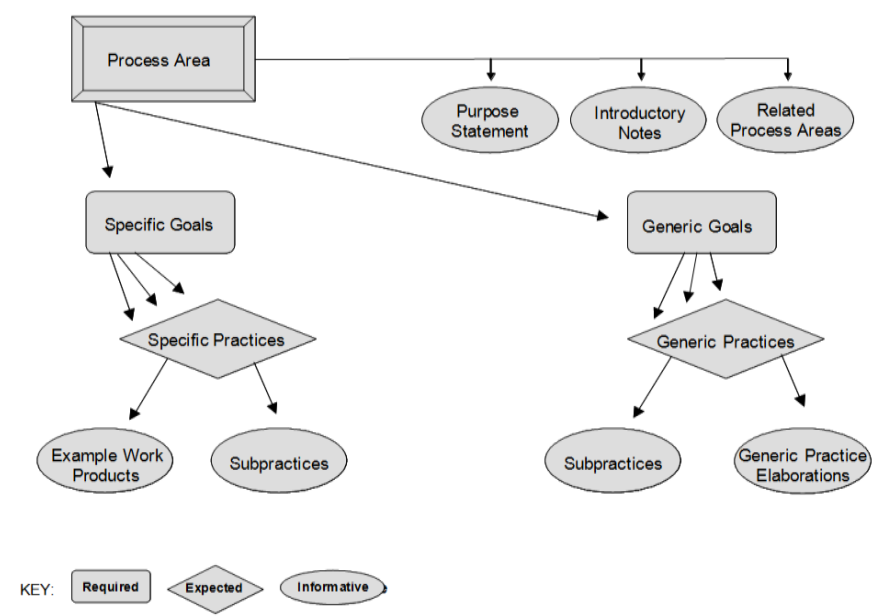

Fig. 1 Overview of the structure of CMMI [15]

Unlike other maturity models, CMMI differentiates between capability levels and maturity levels. Capability levels are organized as follows: (0) incomplete, (1) performed, (2) managed and (3) defined. These levels are indicating capabilities within process areas. Maturity levels, on the other hand, are the foundation for further process optimization. They are organized in five levels: (1) initial, (2) managed, (3)

${ }^{1}$ There is a distinction between core process areas and process areas. The former are pointing to fundamental concepts relevant to all three CMMI variants. The latter, on the other hand, are specific only to one of the respective variants. 
defined, (4) quantitatively managed and (5) optimizing. ${ }^{2}$ Other than the capability levels, maturity levels point to the optimization of the organization in multiple process areas. In CMMI, determining maturity levels is not bound to a specific provider. There are, however, different trainings and certificates (e.g. CMMI instructor).

\section{B. Process and Enterprise Maturity Model (PEMM)}

The PEMM was developed by Dr. Michael Hammer and is used to evaluate enterprises and processes. ${ }^{3}$ For each of these evaluation objects a separate working sheet is available.

The characteristics of the process evaluation, which describes the functionality of a process, are: design (purpose, context, documentation), performers (knowledge, skills, behavior), owner (identity, activities, authority), infrastructure (information systems, human resource systems), and metrics (definition, uses). ${ }^{4}$

The enterprise evaluation, which describes all necessary competences of an enterprise, includes the following aspects: leadership (awareness, alignment, behavior, style), culture (teamwork, customer focus, responsibility, attitude towards change), expertise (people, methodology), and governance (process model, accountability, integration).

Both the process and enterprise evaluation are structured into four maturity levels (P1 to P4). Allocated worksheets should help to determine the actual maturity level. In the worksheets, different statements concerning the abovementioned characteristics are described. If a statement is fulfilled up to $80 \%$, the corresponding box should me marked green. If the statement is only fulfilled between $20 \%-80 \%$, the box is yellow and if the statement is fulfilled less than $20 \%$, it should be marked red. All red statements show further need for improvement.

Additionally, a checklist is available. Using the worksheets and the checklist, the employees themselves could define the maturity level of the processes and of the enterprise. It should be mentioned that the assessment based on the worksheets is only a more general one.

\section{EDEN Maturity Model}

The EDEN maturity model (German abbreviation for: Erfolgreich, Durchgängig, Effizient und Nachhaltig) was developed by the working group BPM Excellence of the BPM Club Germany [17]. The development of the model is based on various models which are applied in the processes of the participating companies. The goal was to develop a maturity model that encompasses different industry sectors and that is applicable to the organizational level with the focus on process

${ }^{2}$ In the organization of capability levels and maturity levels likewise, the levels „managed“ and „defined“ are being applied. The difference is, that maturity levels do not encompass a level (0).

${ }^{3}$ http://www.hammerandco.com/HammerAndCompany.aspx?i $\mathrm{d}=58$

${ }^{4}$ For the working sheets follow: https://hbr.org/2007/04/theprocess-audit/ar/1 management as well as to the evaluation of the process level. EDEN uses 170 criteria which are assigned to nine different dimensions: goals, strategy, methods, organization, measurement, competencies, communication, documentation, IT [17].

A definite benefit of the EDEN maturity model is that complementary modules can be integrated besides the above dimensions. Thus, the model - being rather unspecific in general - can adapt different needs and circumstances. For example, requirements of the Food and Drug Administration, ISO 9000 or ISO / TS 16494 can be integrated. Moreover, other maturity models like CMMI can be inserted to EDEN. Hence, companies can simultaneously evaluate their process management with EDEN and still evaluate their product management according to CMMI-DEV. In this, companies may choose for themselves to which degree certain dimensions ought to be fulfilled (definition of goals). This flexibility allows for a very specific adaption of the general model to concrete needs and requirements of single companies or whole industry sectors.

In EDEN the maturity dimensions are organized in a sixtier evaluation scheme. The assessment of the current state and of goals is being made according to different perspectives which consider the progress and procedure of the company using a matrix to define its position.

\section{SPICE / ISO 15504-5}

The Software Process Improvement and Capability dEtermination (SPICE) maturity model is an international norm since 1992 (ISO / IEC 15504-5) to carry out reviews of business and software processes [18]. As for the other models, it is the aim of SPICE to achieve process improvement. The origin of SPICE lies in the software development. One main characteristic of SPICE is its flexibility and generality. In the first and second part of the standard the fundamental concepts and vocabulary as well as the performance of an assessment are described. It should be noted that only these two parts have a normative character. The other additional parts have an informative nature. In these parts, SPICE is described for other domains like IT service management. In the standard - among others - a description of the manner in which an evaluation of processes is to perform is given [18].

The SPICE evaluation method is not based on a binary response option (yes / no) but on a scale from zero to five. This assessment allows deriving more specific improvement suggestions. The review of this model refers to two dimensions:

- Process dimension: The process dimension covers all the processes and divides them into process categories. Thus, it represents an external process reference model.

- Capability dimension: The capability dimension respectively the framework for the measurement records all relevant process attributes and the assigned skills and allows for an evaluation of the properties and capabilities to verify the achievement of corresponding objectives. 
The assessment is always conducted along processes; each relevant process of an organization can get its own maturity level. The fulfillment of a maturity level depends on whether all criteria of the specific maturity level have been met as described in the level. The degree of the fulfillment of the process attributes is measured in four levels: $0-15 \%$ not achieved, 16-50\% partially achieved, 51-85\% largely achieved, and $86-100 \%$ fully achieved [18]. The measurement of the process attributes is conducted through basic and generic practices. Basic practices on the one hand are activities which contribute to process purposes. These practices must be performed to reach a higher level of fulfillment. On the other hand, there are generic practices that describe activities contributing to process attributes. These practices are not process specific and mainly used to measure the process attributes.

\section{E. $B P M M$}

The Business Process Maturity Model (BPMM) was developed by OMG (Object Management Group) [19]. The primary concern of the BPMM is to provide an evaluation framework for business processes and organizational environments. Additionally, the BPMM evaluates the risks and helps developing roadmaps.

Just as in EDEN, there is a relation to CMMI, since BPMM can be mapped onto CMMI. According to BPMM this is possible because CMMI has a stronger project orientation than BPMM, while BPMM additionally encompasses business processes. BPMM evaluates processes along five maturity levels [19].

The evaluation is based on thirty process areas whereas not every process area is relevant for every level. As an example, level two includes: organizational process leadership, organizational business governance, etc. The other levels (except level one) contain process areas as well, which can be divided into organizational, product and service management, etc. These process areas are classified into five general areas of concern (process areas threads) like organizational process management, etc. In order to achieve a certain maturity level, all the goals and activities described in the respective level and process areas threads have to be met. In the ideal case, institutionalization should be aspired for every process area.

The BPMM can be used to support four different forms of evaluation: Firstly, as a guiding business process improvement program. Secondly, the evaluation of risks developing and deploying enterprise applications. Thirdly, evaluating the capability of suppliers for meeting the necessary service level, price quality, etc. Lastly, the evaluation of the relative position of the enterprise in comparison to the processes in their industry segment.

\section{INTERIM CONCLUSION PART ONE}

Before moving on to domain-specific maturity models, a short conclusion concerning the general models should be given regarding their similarities and possible uses or guidance for a Smart Grid specific maturity model. The previously considered maturity models are frequently used and overall have a focus on process improvement. Some of them were developed in business practice or business alliances and some of them have been standardized. For example, EDEN can be conjunct with CMMI. Whereas other models cannot even be adapted regarding domain-specific demands. A stage based concept is widely accepted concerning the maturity levels. Also, the differentiation between process elements and capability / attributes seems to be common.

\section{SPECIFIC MATURITY MODELS}

This section will introduce some existing maturity models which already focus on the Smart Grid. Additionally, a maturity model for cybersecurity in the energy domain is presented, because the question of a proper cybersecurity cannot be excluded. The following models have been chosen because the research focus lies on Smart Grid technologies.

\section{A. Electricity Subsector Cybersecurity Capability Maturity Model (ES-C2M2)}

The ES-C2M2 was developed by the US Department of Energy and the Department of Homeland Security [20]. The objectives of this model are:

- to strengthen the cybersecurity of the energy domain by evaluating the current capabilities

- to promote cybersecurity capabilities by sharing knowledge and best practices

- to enable the distribution system operators to plan and coordinate their actions.

Therefore, the ES-C2M2 was designed as a self-evaluation model with an adequate toolkit (of course, there are ES-C2M2 facilitators, who can be booked) [21]. As other maturity models, it is designed to fit all needs of different branches regarding its specific focus. Hence, industry subsectors can interpret the model regarding their concrete needs. To ensure an adaption, the model bases on existing cybersecurity standards and frameworks and takes into account the work of different programs and initiatives [20].

The model consists of ten domains, which are divided into different objectives (like approach objectives and management objectives). The approach objectives are best described as domain-specific objectives, whereas the management objectives encompass all common objectives, which are similar in the different domains. Specific practices or practices for the management are pooled in each objective.

Overall, four different maturity (indicator) levels (MIL) are applied in the model. MILs always refer to the domains separately. In order to reach a level, all assigned practices of a domain must be fulfilled. If an organization has risk management MIL1 that means that all practices are at least measured MIL1. The meaning of the different levels is as follows:

- MIL0: The practice does not reach MIL1.

- MIL1: It contains initial practices mostly on a case-bycase basis, depending on the skills and experiences of 
the acting person. Organizational guidance is not assumed.

- MIL2: Initial level of institutionalization of practices. The practices have to be performed according to a documented plan and all relevant stakeholders are identified and involved in the practices. Additionally, all necessary resources are provided. That includes that relevant standards or guidelines have been identified and implemented.

- MIL3: The institutionalization of the practices is further evolved and they are now being managed. The single practices are guided by 'policies' (including standards and guidelines). The employees and authority have each their responsibilities.

In practice, every organization should define a target MIL for each domain to best improve the actual state of the organization. In general, the achieved MILs, the business strategy and the cybersecurity strategy of the organization should be harmonized. Thus, it is neither necessary nor useful always to achieve the highest MIL. The recommended process for applying the ES-C2M2 is structured into four steps (it is assumed that all preparations to use the model have already been conducted):

1. Perform evaluation: Conducting the self-evaluation of the organizational practices against the model practices. It is recommended that all relevant parties participate. A scoring report is generated that informs about the MILs of every domain. A revision and workshops with all participants should be conducted.

2. Analyze identified gaps: Thereafter, gaps should be identified based on the scoring report. The first step of the organization is to clarify whether a gap is relevant for an optimization or if it can be ignored (or has second priority). Accordingly, the organization should identify a target MIL rating (desired capability profile).

3. Prioritize and plan: Now, the organization identifies necessary actions and prioritizes them. Regarding the criteria for the prioritization, different options are possible (cost-benefit analysis, availability of resources, etc.). Afterwards, a detailed plan should be developed.

4. Implement plans: The last step in this circle of applying the model is to implement the chosen actions according to the plan and to review the progress of the implementation. Additionally, a full review can be addressed.

Having completed this process, it can be necessary to start over again to reach higher MILs.

\section{B. SGMM}

Maturity models have already been developed for the energy domain and specifically for the Smart Grid. The SGMM (Smart Grid Maturity Model) was developed by the Software Engineering Institute (SEI) of Carnegie Mellon University [22]. The aim of the SGMM is to provide a common framework for the management to define elements of Smart
Grid transformation. Utilities should use the SGMM to develop a programmatic approach and track their overall processes. This helps utilities to plan their future Smart Grid endeavors, to prioritize their option, and support decision-making processes. The model encompasses eight different domains. In this context a domain means a logical group of Smart Grid related characteristics:

- technology (IT architecture, standards, infrastructure, etc.),

- customer (pricing, customer participation, etc.),

- Strategy - Management - Regulatory (vision planning, governance, etc.),

- organization - structure (training, knowledge management, etc.),

- value chain integration (demand and supply management, etc.),

- societal - environmental (sustainability, efficiency, critical infrastructure),

- grid operations (reliability, security, safety, etc.), and

- work - asset management (monitoring, tracking, maintenance) [22].

To describe the organization in terms of the domain, an overall of 175 characteristics is used. Defining the maturity level of a domain requires the participation in a five step process. The SGMM model uses six maturity levels to rank the outcome of every domain result (see Fig. 2)

\begin{tabular}{|c|c|c|}
\hline $\begin{array}{l}\text { Maturity } \\
\text { Level }\end{array}$ & Name & Maturity Characteristics \\
\hline 5 & Pioneering & Breaking new ground, industry-leading innovation \\
\hline 4 & Optimizing & $\begin{array}{l}\text { Optimizing smart grid to benefit entire } \\
\text { organization; may reach beyond organization; } \\
\text { increased automation }\end{array}$ \\
\hline 3 & Integrating & $\begin{array}{l}\text { Integrating smart grid deployments across the } \\
\text { organization; realizing measurably imrproved } \\
\text { performance }\end{array}$ \\
\hline 2 & Enabling & $\begin{array}{l}\text { Investing based on clear strategy; implementing } \\
\text { projects to enable smart grid (may be } \\
\text { compartmentalized) }\end{array}$ \\
\hline 1 & Initiating & $\begin{array}{l}\text { Taking the first steps, exploring options, } \\
\text { conducting experiments, and developing a smart } \\
\text { grid vision }\end{array}$ \\
\hline 0 & Default & Default level (status quo) \\
\hline
\end{tabular}

Fig. 2 Maturity Levels of SGMM

Summarizing, the SGMM helps utilities to define their future Smart Grid goals, their current state of Smart Grid development and additionally supports the processes of planning, developing roadmaps and implementation for management purposes.

But by applying the SGMM some critical disadvantages emerge. First of all, only certified 'SGMM Navigators' are

${ }^{5}$ https://www.sei.cmu.edu/smartgrid/tools/ 
allowed and deemed qualified to accomplish the SGMM survey and the related workshops [23]. Of course, there are a lot of advantages or disadvantages for this issue. On the one hand, arguments for an institutionalized process are the quality of the survey, comparison of the execution, and evaluation as examples. On the other hand, it could be claimed that the actual evaluation is not transparent; the procedure is not standardized and insofar not available for everyone. The advantages of public standards will not be discussed in the paper but are assumed. Another constraint is the focus on the electrical utilities especially on electric utilities under American regulation. That means, because the role allocation in Europe and US electricity market differs, these differences should be taken into consideration. Furthermore, the SGMM always applies the same questionnaire and the same model to all utilities in the same way. The SGMM offers no specific model for specialized utilities as they are existing in the unbundled European market.

\section{SG IMM}

In addition to the SGMM, the GridWise Architecture Council (GWAC) is developing the Smart Grid Interoperability Maturity Model (SG IMM), a conceptual model with a corresponding tool for organizations engaged in the development of the Smart Grid with focus on interoperability. The idea of the SG IMM is based on the concepts of CMMI and National E-Health Transition Authority (NEHTA) [24].

Since CMMI has been described above, there will be no further detailed review of single aspects in the following. The idea of developing a specific maturity model for the interoperability in Smart Grid derives from the insight, that the interoperability of components and systems in Smart Grid has a crucial position for its further progress.

The goal of SG IMM is hence to provide a maturity model for evaluating and defining the process of achieving interoperability. A crucial intention of GWAC is to establish a model that encompasses multiple organizations but that can yet be used by single companies for self-evaluation purposes. Furthermore, SG IMM is supposed to support the development of new tools and to produce recommendations to increase the degree of interoperability. The model should support methods and processes which serve the integration and maintenance of automated components in the context of Smart Grid. Even though interoperability is a very complex issue, the currently developed model should be configured in a way that allows for creating understanding and benefit on a high level of abstraction, as well as on a detailed level [25].

The design of maturity levels is supposed to be oriented towards CMMI and NEHTA. NEHTA is composed of six maturity levels from level 0 (no processes to support crossorganizational interoperability) to level 5 (continuous interoperability innovations, enables community / social goals).

The structure of the SG IMM is based on the GridWise Interoperability Context-Setting Framework with additionally identified areas that are crosscutting towards the interoperability categories. These crosscutting issues are: configuration and evolution (shared meaning of content, resource identification, discovery and configuration, system evolution and scalability), operation and performance (time synchronization and sequencing, transaction and state management, quality of service), security and safety (security and privacy, logging and auditing, system preservation). A first simplified interoperability framework is described as follows (see Fig. 3):

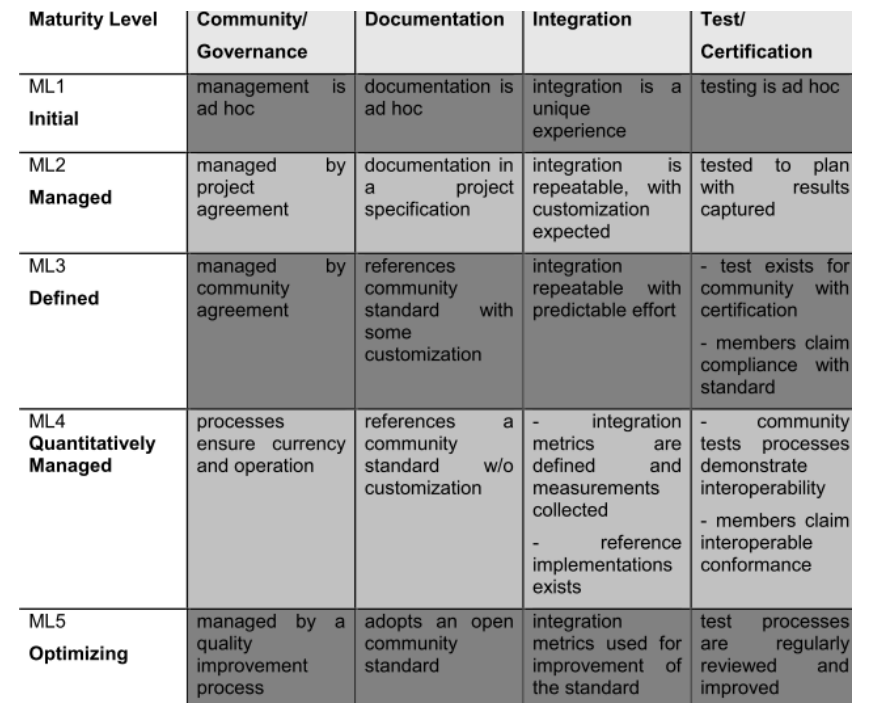

Fig. 3 Maturity levels of SG IMM

Each issue area has related cross-cutting issue goals, for instance in the category 'information model' vocabularies, concepts, and definitions are agreed on by all parties. Additionally each interoperability category (organizational, informational and technical) has subordinated interoperability goals, e.g. a common understanding of quality of service, time, and scheduling exists. Over 70 metric statements were developed for the nine cells of the framework. The actual application of the SG IMM is oriented on the NEHTA Interoperability Maturity Model [26]. The SG IMM is developed for different applications in the electrical power system. The connection between these options is, that the application is concerned with at least two information systems or devices. Sample applications of the SG IMM are energy market operations, enterprise Smart Grid applications, and retail service provider [26].

\section{INTERIM CONCLUSION PART TWO}

Before heading on to present a first overview of classification schemes for a comparison of maturity models, a short summary concerning the domain-specific maturity models is given, especially regarding the difference between the SGMM and SG IMM. One of the main differences is that the SGMM is a management tool to support utilities' Smart Grid implementation and planning. It refers to interoperability requirements in the maturity level design but it does not concentrate especially on achieving it. This is the focus of the SG IMM instead.

Referring back to the question why a new model should be developed, it is now time to give a short reply. The SGMM is a complex and detailed model. One of the main deficits is that it 
lacks some capabilities to be applicable for European purposes [13]. This refers especially to the 'Unbundling' in Europe and the SGMM approach to be suitable for a wide range, i.e. the energy industry altogether. And that leads to the second point. The SGMM is made for the electrical industry. Improving the approach to enable assessment of projects, roadmaps and agendas would be an additional benefit. The SG IMM's focus lies basically on assisting stakeholders to achieve interoperability [13]. Regarding the SG IMM and the SGMM it should be noted that the methodology how to gather the factors are not explained on detail. Another aspect (and probably the main aspect) is that the models do not provide an approach that makes a quantitative survey of the level of the Smart Grid development possible.

\section{DRAFT OF A CLASSIFICATION SCHEME FOR A COMPARISON OF MATURITY MODELS}

In this section a possible classification scheme is presented. The classification scheme should be used to make maturity models comparable but not to rate the maturity models themselves. The aim of the comparison is first to get an overview of possible and seemingly mandatory elements of a maturity model and second, to identify the diversity of specific manifestations of the single elements of a maturity model. This preparatory work then helps to decide which elements a new maturity model or an advancement of an existing one can include. The reason for this proceeding is, that best practice of the maturity models should be recognized, e.g. in the development of the SG IMM the SGMM and the NEHTA are consulted and integrated.

For the comparison of maturity models different criteria are possible. Before choosing a model as a basis for further progression, the following criteria-related questions should not only be addressed to existing models, but also they should be answered by the developer (possible questions addressing the developer view are in brackets). Additionally, it should be remarked that the questions cover only some aspects of the following clusters: the general scope of the model (objectives, application area, maturity levels, adaptability, target group, etc.), quality management (certification, documentation etc.), and process (conduction of an assessment, documentation, accessibility, methods and tools). Thereby, the questionnaire does not reflect on the timeline in the developing process. Also, the aspect of defining concrete criteria is not sufficiently addressed. The reason therefore lies in the step after step process of developing a maturity model. Without determining necessary key aspects of the future model, a further outline of the addressable criteria is not promising. If it could be argued that most maturity models address organizational, processorientated and some specific characteristics, but as outlined before the aim is to develop a Smart Grid specific model which has to include technical development aspects as well as requirements. It should be noted that the following questions for the developer are not exhaustive.

- Main objectives: What benefit or information does the maturity model produce for the organization, e.g. localization on the Smart Grid landscape? (Why is a new maturity model necessary? Which is its main objective?)

- Target group: Which organization of which size should apply the model? (Which is the target group of the model? Is the target group consisted only of SME? Or large enterprises?)

- Driver of application: Why does someone want to / should apply the model? (Which internal or external requirements drive the application?)

- Application area: Is the model domain-independent (general) or is it specific for a domain or an even more specific question? (Should the model be general or domain-specific?)

- Maturity level: How many and which maturity levels does the model include?

- Assessment objects: What kind of objects / competences is measured? How is their substructure? (What kind of specific objects should be in the focus of the model? Or should it be with a wholeness claim?)

- Origin: Which branch or alliance developed the maturity model? Were they mainly academics, practitioners or even government officials? Or a combination of these? (Which stakeholders should or must be involved? Should a model be tested by a certain stakeholder?)

- Adaptability: Is the model adaptable for specific purposes? Or for the needs of a specific branch / domain? (Should the model be adaptable? Or even compatible with other models?)

- Certification: Is a certification available? Which quality does the certification have? (Should a certification be introduced? Who should supervise the certification process?)

- Conduction of an assessment: Who is able and allowed to conduct an assessment? Which training is necessary or possible? (Who should be allowed to conduct the assessment? Which tools must be provided?)

- Methods and tools of assessment: Which tools are available? Are they qualitative or quantitative? What other methods are applied? (Which tools and methods will be used and provided?)

- Documentation: Is the documentation continuous? What kind of documentation is used? (How is the documentation planned? Does the plan match the required methods and tools?)

- Standardization: Is the maturity model (or parts of it) standardized? (Will the maturity model (or parts of it) be handed to standardization committees?)

- Accessibility: Is the model itself and all relevant documents accessible? Or are some elements (like the evaluation standards) not available? (To whom do the intellectual property rights belong?) 
- Evaluation / empirical foundation: ${ }^{6}$ Was the model itself evaluated? Was the model empirically analyzed? (How can the developed model be evaluated?)

\begin{tabular}{|c|c|c|c|c|c|c|}
\hline Model & Main objectives & $\begin{array}{l}\text { Target } \\
\text { Group }\end{array}$ & $\begin{array}{l}\text { Method and } \\
\text { Tools }\end{array}$ & $\begin{array}{l}\text { Maturity } \\
\text { Scale }\end{array}$ & Origin & Application area / Focus \\
\hline$\overline{\mathrm{CMMI}}$ & $\begin{array}{l}\text { Process } \\
\text { Optimization }\end{array}$ & $\begin{array}{l}\text { Sector- } \\
\text { Independent }\end{array}$ & $\begin{array}{l}\text { Questionnaire, } \\
\text { Metrics, Indicators, } \\
\text { and Attributes, } \\
\text { Online Tool }\end{array}$ & Five & $\begin{array}{l}\text { Politics, } \\
\text { Research } \\
\text { Institute }\end{array}$ & $\begin{array}{l}\text { One General Framework; } \\
\text { and Specific Models } \\
\text { Processmanagement: } \\
\text { Acquisition, Service, and } \\
\text { Development }\end{array}$ \\
\hline PEMM & $\begin{array}{l}\text { Benchmarking and } \\
\text { Roadmap Tool for } \\
\text { Organizations }\end{array}$ & $\begin{array}{l}\text { Sector- } \\
\text { Independent }\end{array}$ & $\begin{array}{l}\text { Questionnaire, } \\
\text { Metrics, Indicators, } \\
\text { and Attributes }\end{array}$ & Five & Consultancy & Enterprise Processes \\
\hline EDEN & $\begin{array}{l}\text { Process } \\
\text { Optimization }\end{array}$ & $\begin{array}{l}\text { Sector- } \\
\text { Independent }\end{array}$ & $\begin{array}{l}\text { Metrics, Indicators, } \\
\text { and Attributes }\end{array}$ & Six & Consortium & $\begin{array}{l}\text { Process Level and } \\
\text { Organizational Level }\end{array}$ \\
\hline SPICE & $\begin{array}{l}\text { Process } \\
\text { Optimization; } \\
\text { Classification of } \\
\text { Process Capabilities }\end{array}$ & $\begin{array}{l}\text { Sector- } \\
\text { Independent }\end{array}$ & $\begin{array}{l}\text { Metrics, Indicators, } \\
\text { and Attributes }\end{array}$ & $\begin{array}{l}5 \text { Level and } \\
\text { Rating Scale }\end{array}$ & $\begin{array}{l}\text { Standardization } \\
\text { Committee }\end{array}$ & $\begin{array}{l}\text { Information Technology and } \\
\text { Business Management }\end{array}$ \\
\hline ВРMM & $\begin{array}{l}\text { Business Process } \\
\text { Optimization }\end{array}$ & $\begin{array}{l}\text { Sector- } \\
\text { Independent }\end{array}$ & $\begin{array}{l}\text { Questionnaire, } \\
\text { Metrics, Indicators, } \\
\text { and Attributes }\end{array}$ & Five & Consortium & $\begin{array}{l}\text { Process Level and } \\
\text { Organizational Level }\end{array}$ \\
\hline $\begin{array}{l}\text { ES- } \\
\text { C2M2 }\end{array}$ & $\begin{array}{l}\text { Improvement of } \\
\text { Cybersecurity }\end{array}$ & $\begin{array}{l}\text { Organizations } \\
\text { in the } \\
\text { Electricity } \\
\text { Market }\end{array}$ & $\begin{array}{l}\text { Reference Material, } \\
\text { Implementation } \\
\text { Guidance, Metrics, } \\
\text { Indicators, and } \\
\text { Attributes }\end{array}$ & Four & Politics & $\begin{array}{l}\text { Energy Sector and } \\
\text { Cybersecurity }\end{array}$ \\
\hline SGMM & $\begin{array}{l}\text { Classification Smart } \\
\text { Grid Development }\end{array}$ & $\begin{array}{l}\text { Energy } \\
\text { Domain }\end{array}$ & $\begin{array}{l}\text { Metrics, Indicators, } \\
\text { and Attributes }\end{array}$ & Five & $\begin{array}{l}\text { Research } \\
\text { Institute }\end{array}$ & Smart Grid \\
\hline $\begin{array}{l}\text { SG } \\
\text { IMM }\end{array}$ & $\begin{array}{l}\text { Classification of } \\
\text { Smart Grid } \\
\text { Interoperability } \\
\text { Development }\end{array}$ & $\begin{array}{l}\text { Energy } \\
\text { Domain }\end{array}$ & $\begin{array}{l}\text { Metrics, Indicators, } \\
\text { and Attributes }\end{array}$ & Five & Consortium & $\begin{array}{l}\text { Interoperability and Smart } \\
\text { Grid }\end{array}$ \\
\hline
\end{tabular}

Fig. 4 Overview of Maturity Models

The above overview (see Fig. 4) of possible classification criteria for a comparison of maturity models are based on [11], [27], [28], and [29]. It is appropriate to define even more subcriteria regarding some of the mentioned criteria.

The benefit and aim of this classification scheme is, that if a new model should be developed (e.g. from a consortium or an organization) and some general questions have to be answered in accordance with all of the participants, this scheme can be used as a questionnaire. Thereby it is to recommend to involve different sectors of the organizations, i.e. fields of activity. A systematic preparation and conduction is one of the key aspects for developing a coherent maturity model.

\footnotetext{
${ }^{6}$ The criteria ,evaluation / empirical foundation' can be seen as a quality criteria of maturity models because it provides information on the applicability and practical relevance.
}

\section{OUTLOOK AND CONCLUSION}

Referring to the above sections, the focus areas of maturity models under construction are grid appropriate ICT, distribution layer, cybersecurity, and interoperability. The unique features of the models are the concentration on the distribution layer and all its relevant stakeholders. The maturity model should be applicable by utilities, OEMs, R\&D, etc. Thereby it is a domain-specific but still holistic model, that allows to measure cross-cutting issues (like interoperability and security) and more specific ones. In this, it must be consistent with the new demands of the unbundled European market. Therefore, a useful step would be to perform an aggregation of the individual models in order to cover all relevant issues.

As a notation basis it will be tried to use the SGAM framework which allows a detailed modeling of variants of Smart Grid functionalities in their relation to interoperability. An option for integrating a maturity reference model to SGAM is an extension of the Use Case template. IEC / PAS 62559 already contains lots of entities, which can be used for an assessment. The template serves, additionally, as a perfect hierarchical-cross-position-cutting basis for discussion and information exchange. 
A further working result which will be considered in developing the model is the work of [13]. They outline a process of developing an adaptive maturity model based on the SGMM. Therefore, the SGMM is extended with an adaption mechanism.

Additionally, it should be mentioned that during the ongoing process the concept of migration paths will be used to define the maturity levels for the maturity models. Migration paths offer the advantage to describe technology development steps for different technology fields. Considering the dependencies between the development steps of the technology fields, a reasonable basis is laid out to cluster the necessary development steps into criteria. These clustered criteria could define which tasks / solutions have to be fulfilled to reach a specific maturity level.

Summarized, the approach to combine the SGAM including the IEC / PAS 62559 and a developed maturity model thereupon is seen as a useful approach. After the further development of comparative criteria, the actual comparison of the existing maturity models will be conducted. The questions for the developers of maturity models defined above have to be answered simultaneously. The target of the comparison is to identify an existing model to which adaptions for developing a new one can be made. Naturally, the chosen model should be in accordance with the vision of the new one as much as possible. After selecting a model, the complementary aspects and elements need to be worked out. This might concern the relevant domains in general or some specific sub-elements.

\section{REFERENCES}

[1] M. Uslar, C. Rosinger, and S. Schlegel, ,,Anwendung des NISTIR 7628 für Informationssicherheit im Smart Grid Architecture Model (SGAM),“ VDE Kongress, 2014.

[2] E-Bridge, IAEW, and OFFIS, „Moderne Verteilernetze für Deutschland (Verteilernetzstudie),“ 2014

[3] J. Drexhage, and Deborah Murphy, „Sustainable Developmetn: From Brundtland to Rio 2012; UN Background Paper, 2010.

[4] Project Management Institut, "Organizational Project Management Maturity Model (OPM3). Knowledge Foundation”, 2003.

[5] T. Mettler, and P. Rohner, "Situational Maturity Models as Instrumental Artifacts for Organizational Design," Proceedings of the 4th international conference on design science research in information systems and technology, 2009.

[6] J. Becker et al, „Maturity Models in Information Systems Research: Literature Search and Analysis, " Communications of the Association for Information Systems, vol. 21 no. 1, 2011.

[7] G. Lahrmann, F. Marx, T. Mettler, R. Winter, and F. Wortmann, „Inductive Design of Maturity Models: Applying the Rasch Algorithm for Design Science Research“, in: H. Jain, AP. Sinha, and P. Vitharana (eds.): DESRIST 2011, LNCS 6629, pp. 176-191, 2011.

[8] F. Marx, ,Entwicklung eines Reifegradmodells zur IT-Unterstützung der Unternehmensführung,“ Dissertation, Universität St. Gallen, 2011.
[9] G. Akkasoglu, "Methodik zur Konzeption und Applikation anwendungsspezifischer Reifegradmodelle unter Berücksichtigung der Informationsunsicherheit,“ Dissertation, Friedrich-AlexanderUniversität Erlangen, Nürnberg, 2014.

[10] J. Pöppelbuß, and M. Röglinger, "What Makes a Usefull Maturity Model? A Framework of General Design Principles for Maturity Models and its Demonstration in Business Process Management", unknown (http://is2.lse.ac.uk/asp/aspecis/20110028.pdf).

[11] T. Bruin, M. Rosemann, R. Freeze, and U. Kulkarni, "Understanding the Main Phases of Developing a Maturity Assessment Model," $16^{\text {th }}$ Australasian Conference on Information Systems, Sydney, 2005.

[12] J. Becker, R. Knackstedt, and J. Pöppelbuß, "Developing Maturity Models for IT Management - A Procedure Model and its Application," Business \& Information Systems Engineering (BISE), 1 (3), pp. 213222.

[13] S. Rohjans, M. Uslar, A. Cleven, R. Winter, and F. Wortmann, "Towards an Adaptive Maturity Model for Smart Grids," $17^{\text {th }}$ Power Systems Computation Conference, Stockholm, 2011.

[14] CMMI Product Team, „CMMI for Development, Version 1.3,“ Technical Report, Software Engineering Institut, November 2010.

[15] CMMI Product Team, „CMMI for Services, Version 1.3,“ Technical Report, Software Engineering Institut, November 2010.

[16] CMMI Product Team, „CMMI for Acquisition, Version 1.3,“ Technical Report, Software Engineering Institut, November 2010.

[17] BPM Maturity Model EDEN e.V., "EDEN - Reifegradmodell für Prozessmanagement," 2009.

[18] P.-R. Wentzel, J. Schmied, U. Hehn,. And M. Gerdom, „SPICE im Unternehmen einführen. Ein Leitfaden für die Praxis,“ dpunkt.Verlag, 2010.

[19] Object Management Group, „Business Process Maturity Model (BPMM), Version 1.0,“2008.

[20] Carnegie Mellon University, "Electrity Subsector Cybersecurity Capability Maturity Model (ES-C2M2), version 1.0,” 2012.

[21] Carnegie Mellon University, "Cybersecurity Capability Maturity Model (C2M2), Facilitator Guide, Version 1.1," 2014.

[22] The SGMM Team, "SGMM Model Definition. A Framework for Smart Grid Transformation. Version 1.2," Technical Report, 2011.

[23] Carnegie Mellon University, "Smart Grid Maturity Model. SGMM Compass Assessment Survey, Version 1.2," 2011.

[24] S. Widergren, A. Levinson, J. Mater, and R. Drummond, "Smart Grid Interoperability Maturity Model," IEEE, 2010.

[25] M. Knight, S. Widergren, J. Mater, and A. Montgomery, "Maturity Model for Advancing Smart Grid Interoperability," Innovative Smart Grid Conference 2013, IEEE 2012.

[26] The GridWise Architectur Concil, "Smart Grid Interoperability Maturity Model Beta Version," 2011

[27] F. Ahlemann, C. Schroeder, and F. Teuteberg, „Kompetenz- und Reifegradmodelle für das Projektmanagement,“ ISPRI-Arbeitsbericht, Nr. 01/2005.

[28] J. Becker, R. Knackstedt, and J. Pöppelbuß, "Vergleich von Reifegradmodellen für die hybride Wertschöpfung und Entwicklungsperspektiven," MKWI 2010 - Integration von Produkt und Dienstleistung - Hybride Wertschöpfung, 2010.

[29] F. Marx, F. Wortmann, and H. Mayer, „Ein Reifegradmodell für Unternehmenssteuerungssysteme. Fünf Reifegrade als Grundlage der systematischen Entwicklung,“ Wirtschaftsinformatik 4/2012, S. 189204, 2012. 